\title{
Role of Diffusion Weighted Magnetic Resonance Imaging in Differentiation between Benign and Malignant Vertebral Body Collapse
}

\author{
NARDINE N. HELMY, M.Sc.*; MOHAMED A. HASSAAN, M.D.*; AMR Y. SAKR, M.D.** and \\ MOHAMED T. ALI, M.D.* \\ The Departments of Radiology* and Radiotherapy**, Faculty of Medicine, Cairo University
}

\begin{abstract}
Background: In recent years, MRI has increasingly become the modality of choice for imaging of musculoskeletal disorders. Diffusion weighted MR sequences provide microscopic information to supplement the macroscopic information provided by conventional sequences. It is a non invasive imaging technique which is suitable for probing the physical structure of a biologic tissue at a microscopic level and it exploits the random, translational motion of water protons in a biologic tissue, which reflects the tissue specific diffusion capacity and can be used for tissue characterization.
\end{abstract}

Aim of Work: The aim of this study is to determine the value of Diffusion Weighted Imaging (DWI) in differentiation between different causes of vertebral collapse.

Patients and Methods: This is a prospective study carried out in Radio-Diagnosis Department, Faculty of Medicine, Cairo University between August 2014 and February 2016 for patients diagnosed with vertebral body collapse. A total number of 35 patients (20 males and 15 females) with age range $18-74$ (average 52).

The MRI sequences obtained were sagittal T1WI, T2WI, STIR and axial T1WI, T2WI \& DWI ( \pm post contrast images in some patients). Bone marrow signal intensity of the collapsed vertebra was analyzed by comparing its signal intensity with the signal intensity of the intervertebral disc, fat and muscle tissue on T1-weighted images, the signal intensity of the affected veteba was also inspected on DWI then ADC values were automatically calculated using the software provided by the MR scanner manufacturer (Diffusion Calculation: Philips Medical Systems ${ }_{3}$ and the ADC quantitative parameter was expressed in: $10 \mathrm{~mm} / \mathrm{s}$.

Results: Our study included 35 patients who were diagnosed with vertebral body collapse. Qualitative evaluation of the lesion contrast in diffusion-weighted MRI of the vertebral column has been shown to be valuable for the differentiation of lesion etiology; however, visual assessment of high signal intensity was not specific for malignancy.

Correspondence to: Dr. Nardine N. Helmy, The Department of Radiology, Faculty of Medicine, Cairo University
On the other hand the quantitative assessment by measuring the ADC value was able to distinguish different types of vertebral collapse.

In our study, there was statistically Highly Significant (HS) difference between malignant and the following benign causes of vertebral collapse; acute fracture, chronic osteoporotic collapse and pyogenic spondylodiscitis. There is also statistically significant difference (S) between malignant and TB spondylodiscitis lesions according to ADC values.

Conclusion: Diffusion weighted MRI can be used as a reliable tool in differentiation between different causes of vertebral body collapse. DWI could be applied as a cost effective substitute for the gadolinium enhanced scan especially in patients with contraindication for contrast administration.

Key Words: DWI - Osteoporotic collapse - Compression fracture-ADC-Malignant collapse.

\section{Introduction}

A VERY important diagnostic question in MRI of the spinal column, which is notoriously difficult to answer with conventional MRI sequences, is the differentiation of benign and malignant vertebral compression fractures, i.e. of fractures caused either by, e. g., osteoporosis or by neoplastic bonemarrow lesions, respectively [1].

There are no reliable signal differences allowing discrimination of benign osteoporotic and neoplastic vertebral compression fractures when conventional pulse sequences are used and they are both predominantly found in elderly patients. Therefore, it is important to find additional qualitative or quantitative criteria for more reliable distinction between these two fracture types [2].

DWI is a fast MRI sequence, which offers without any contrast media injection, assessment 
of various types of spine vertebral and discal lesions [3].

The signal intensity of DWI relies on the stochastic Brownian motion, or self diffusion of water molecules at a microscopic level within tissues. Extracellular water has more freedom, or is less impeded in its motion, in comparison to intracellular water molecules, which are limited in their motion by intracellular organelles, macromolecules and cell membranes. Areas with higher cellularity (and therefore more intracellular components and cell membranes) will demonstrate impeded molecular water mobility [4].

Malignant fractures show restricted diffusion-that is, low ADCs and high SI on DW images-because dense tumor cell packing should lead to a smaller and more restricted extracellular space and to decreased diffusion capability. Acute osteoporotic fractures, on the other hand, mostly show increased diffusion with high ADCs and low SIs on DW images because water proton mobility is increased as a result of the bone marrow edema [2].

Quantitative DWI and measurement of the ADC of the vertebral lesion is considered as an important approach as well. ADC of benign, osteoporotic fractures is generally higher than the ADC of metastatic lesions or malignant fractures caused by tumor infiltration [5].

Aim of the work: The aim of this study is to determine the value of Diffusion Weighted Imaging (DWI) in differentiation between different causes of vertebral collapse.

\section{Patients and Methods}

This is a prospective study carried out in RadioDiagnosis Department, Faculty of Medicine, Cairo University between August 2014 and February 2016 for patients diagnosed with vertebral body collapse. Informed consent was obtained for this ethics committee-approved study. A total number of 35 patients ( 20 males and 15 females) with age range 18-74 (average 52).

\section{Inclusion criteria:}

- Patients diagnosed with vertebral body collapse.

\section{Exclusion criteria:}

- Patients with pacemaker.

- Patients with claustrophobia.

\section{Patients were subjected to the following:}

- Clinical assessment:

Short medical history was taken from out patients, however; more detailed clinical and laboratory data were obtained from in-patients.

\section{- Radiological investigations:}

A- MRI examination: All patients were subjected to MRI examination. Some patients received IV contrast "gadolinium D.T.P.A".

B- Plain X-ray, CT, or bone scan were done for some of the patients.

C- Pathological examination results were available in some cases form which biopsy was taken during our study.

\section{MR imaging technique:}

- Imaging was performed using a standard 1.5 Tesla unit (Intera and Achieva, Philips).

- A sense spine coil was used.

A- Routine MRI sequences of spine:

- Sagittal T1WI, T2WI \& STIR.

- Axial T1WI \& T2WI.

- Contrast enhanced images (in some patients) after manual intravenous administration of $0.1 \mathrm{mmol} / \mathrm{kg}$ of gadolinium-DTPA.

\section{B- DWI of spine:}

DWI was performed with free breathing and inversion recovery single-shot spin-echo echoplanar sequences (TR/TE, 9000/68; number of slices, 12; slice thickness, $5 \mathrm{~mm}$; gap, 0mm; flip angle, $90^{\circ} ; \mathrm{FOV}, 300 \mathrm{~mm}^{2}$ ). We applied 3 diffusionsensitizing gradients with $b$-values of 0,50 and $800 \mathrm{~s} / \mathrm{mm}^{2}$. The total imaging time was $6: 09 \mathrm{~min}$.

\section{Image analysis:}

All images were loaded to a workstation (Philips Medical Systems). Bone marrow evaluation and image interpretation were performed.

\section{A- Qualitative analysis:}

Bone marrow signal intensity was qualitatively analyzed by visually comparing its signal intensity with the signal intensity of the non-degenerated intervertebral disc, subcutaneous fat and muscle tissue depicted on T1-weighted images.

\section{B- Quantitative analysis:}

The radiologist quantitatively evaluated the bone marrow signal intensity by performing measurements in Regions of Interest (ROI). 
The ROI was drawn as large as possible placed in the antrocentral aspect of vertebral body to avoid vertebral end plate degenerative changes and basivertebral vein plexus. In each patient at least 3 ROI were applied.

ADC values were automatically calculated using the software provided by the MR scanner manufacturer (diffusion calculation: Philips Medical Systems) and the ADC quantitative parameter was expressed in: $10^{-3} \mathrm{~mm} / \mathrm{s}$. The average ADC value of the three regions of interest of each patient was calculated and recorded. The final diagnosis which was made on the basis of biopsy results or results of clinical and radiologic follow-up was used as the "gold standard" to classify the vertebral marrow lesions.

\section{Results}

A total number of 35 patients ( 20 males and 15 females) with age range 18-74 (average 52) diagnosed with vertebral body collapse were radiologically evaluated.

\section{Classification of vertebral collapse:}

Patients included in the study were 16 of benign nature and 19 of malignant nature (Table 1). Diagnosis is based on clinical, radiological and histopathological data. The 21 patients with benign collapse included 7 patients with benign fracture and 9 patients with inflammatory/infectious collapse.

Table (1): Classification of the vertebral bone marrow abnormalities.

\begin{tabular}{lc}
\hline Group & No. of patients \\
\hline Benign fracture & 7 \\
Inflammatory & 9 \\
Malignant & 19 \\
\hline
\end{tabular}

\section{Benign wedging/fracture:}

A total of seven cases with benign vertebral body collapse were found: Four patients with acute traumatic fracture and three cases with chronic osteoporotic collapse.

On DWIs, acute traumatic fractures revealed high signal intensity while the chronic osteoporotic collapse revealed low signal intensity. The mean ADC value of acute traumatic fracture was high (mean; $1.638 \times 10^{-3} \mathrm{~mm}^{2} / \mathrm{s}, \mathrm{SD} \pm 0.09 \times 10$ $\mathrm{mm}^{2} / \mathrm{s}$ ) while chronic osteoporotic collapse węre of low ADC values (mean; $0.305 \times 10 \mathrm{~mm} / \mathrm{s}$, $\left.\mathrm{SD} \pm 0.14 \times 10^{-3} \mathrm{~mm} / \mathrm{s}\right)$.

\section{Inflammatory lesions:}

On DWIs, all lesions in the inflammatory group revealed high signal intensity. The mean ADC value of pyogęnic spondylodiscitis was high (męan; $1.454 \times 10 \mathrm{~mm} / \mathrm{s}, \mathrm{SD} \pm 0.16 \times 10 \mathrm{~mm} / \mathrm{s})$ while TB spondylodiscitis twere of lower ADC values (mean; $1.191 \times 10^{-3} \mathrm{~mm} / \mathrm{s}, \mathrm{SD} \pm 0.29 \mathrm{X}$ $\left.10^{-3} \mathrm{~mm} / \mathrm{s}\right)$.

\section{Malignant neoplastic lesions:}

A total of 19 cases with malignant vertebral lesions were found. On DWIs, malignant lesions

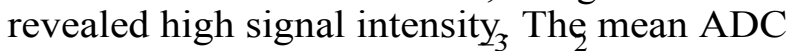
value ${ }_{-3}$ was (mean; $0.982 \times 10 \mathrm{~mm} / \mathrm{s}, \mathrm{SD} \pm 0.17$ $\mathrm{X} 10 \mathrm{~mm} / \mathrm{s}$ ).

\section{Summary of ADC values of the different groups:}

Table (2): ADC values of different causes of vertebral collapse.

\begin{tabular}{|c|c|c|c|c|}
\hline \multirow[t]{2}{*}{$\begin{array}{l}\text { Different causes } \\
\text { of vertebral collapse }\end{array}$} & \multicolumn{2}{|c|}{$\begin{array}{c}\stackrel{\mathrm{ADC}}{-3} \mathrm{~mm}^{2} / \\
\mathrm{sec})\end{array}$} & \multicolumn{2}{|c|}{$t$-test } \\
\hline & Mean & $\pm \mathrm{SD}$ & $p$-value & Sig. \\
\hline Malignant lesion & 0.982 & 0.170 & & \\
\hline Traumatic/acute fracture & 1.638 & 0.089 & $<0.001$ & HS \\
\hline Chronic osteoporotic collapse & 0.305 & 0.138 & $<0.001$ & HS \\
\hline Pyogenic spondylodiscitis & 1.454 & 0.157 & $<0.001$ & HS \\
\hline TB spondylodiscitis & 1.191 & 0.288 & 0.034 & S \\
\hline
\end{tabular}

Table (2) shows statistically Highly Significant (HS) difference between malignant and the following benign causes of vertebral collapse; acute fracture, chronic osteoporotic collapse and pyogenic spondylodiscitis. There is also statistically significant difference (S) between malignant and TB spondylodiscitis lesions according to ADC Fig. (1).

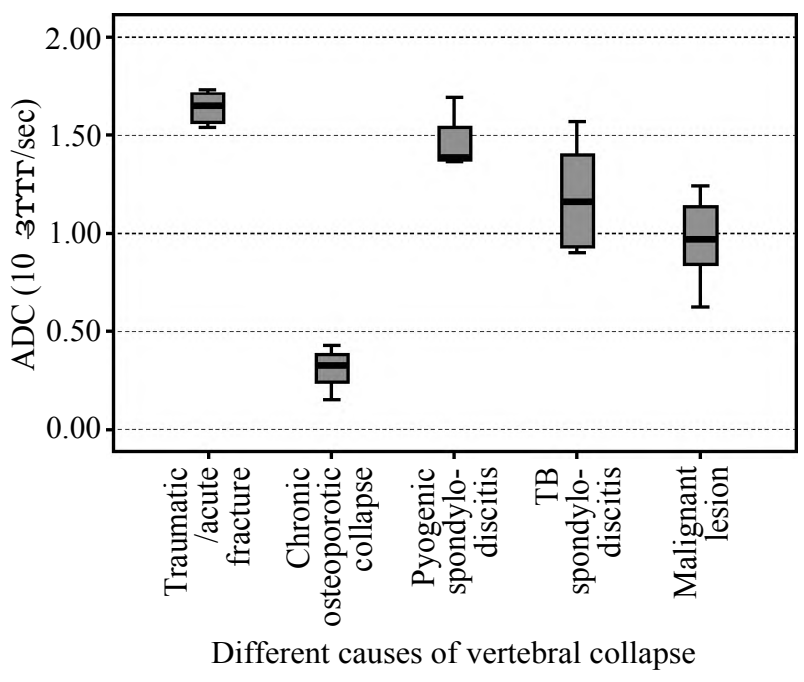

Fig. (1): ADC values of different causes of vertebral collapse. 


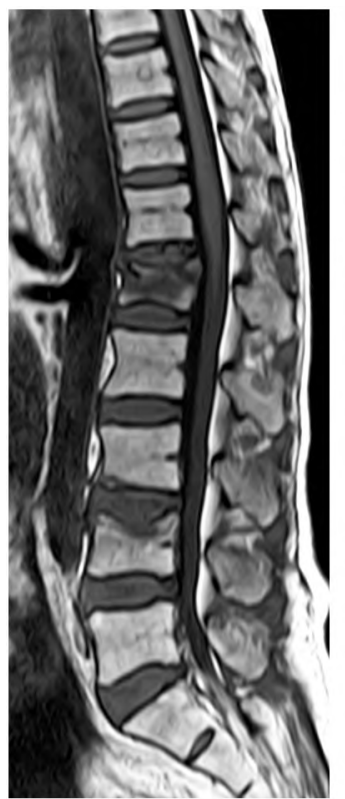

(A)

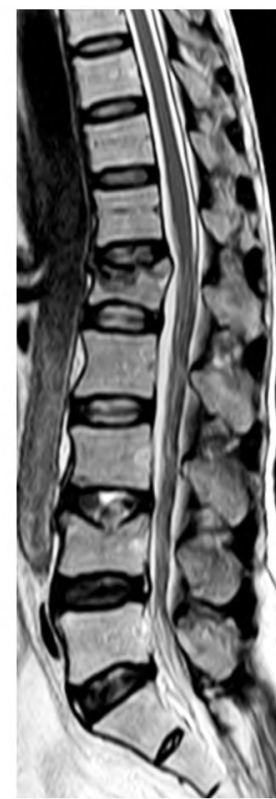

(B)

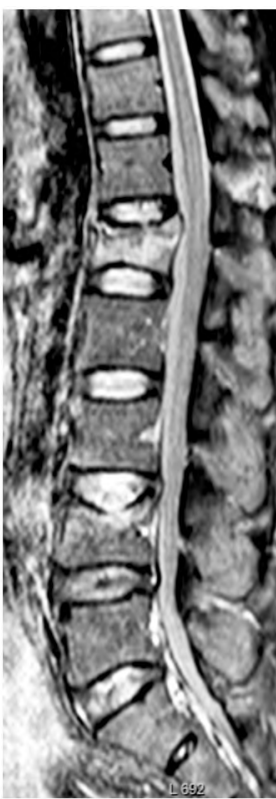

(C)

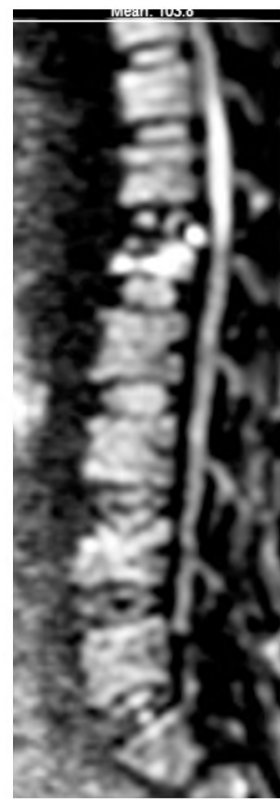

(D)

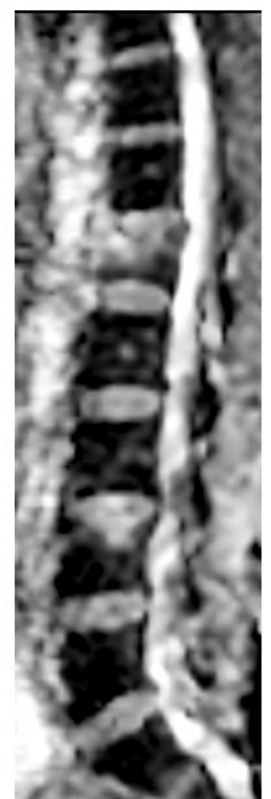

(E)

Fig. (2): A 55 year old male known to have liver cirrhosis presenting with back pain. MRI of the lumbosacral spine: (A) T1, (B) T2, (C) STIR (D) DWI and (E) ADC sagittal images revealing L1 benign vertebral fracture with hyperintense signal of the affected vertebra with no drop out of signal on ADC images. ADC value: 1.727 X $10 \mathrm{~mm} / \mathrm{s}$.

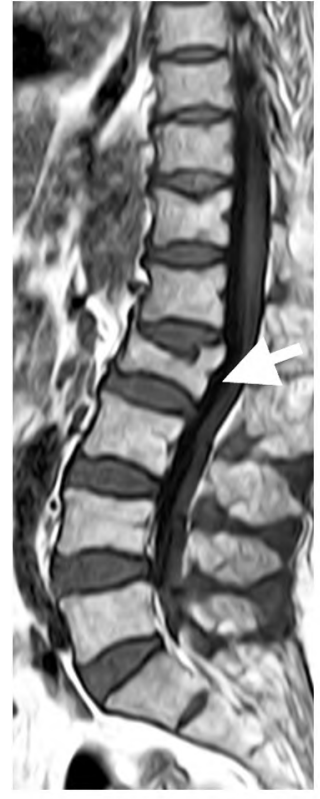

(A)

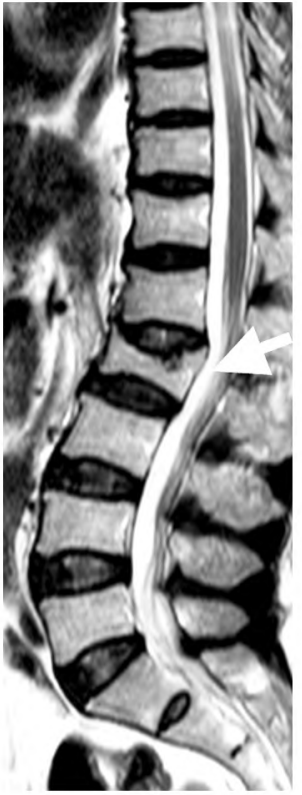

(B)

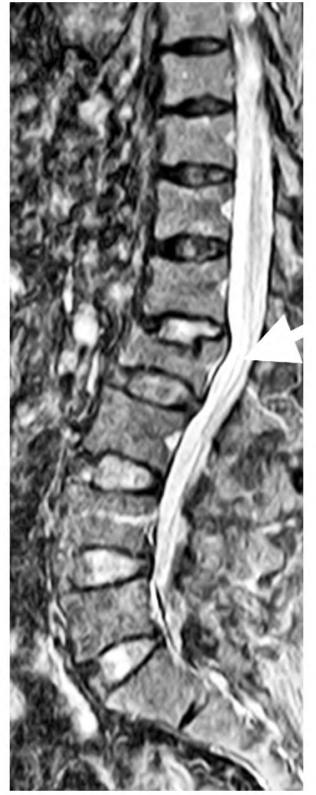

(C)

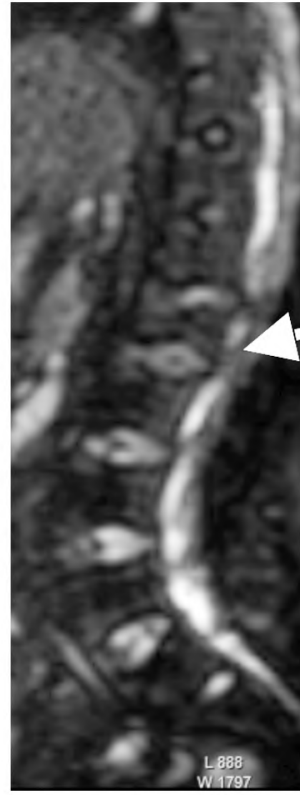

(D)

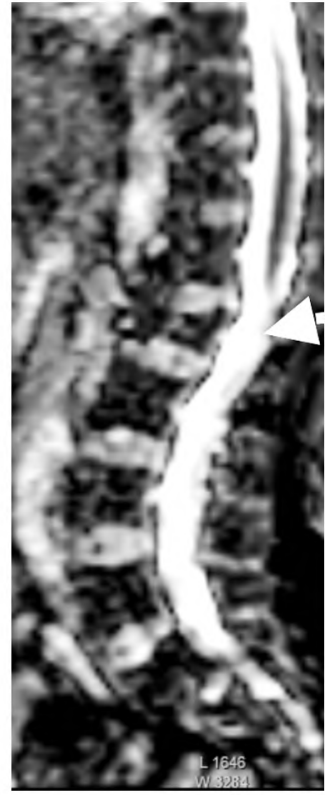

(E)

Fig. (3): A 67 year old female presenting with back pain. MRI of the dorsolumbar spine: (A) T1, (B) T2, (C) STIR (D) DWI and (E) ADC sagittal images revealing L2 vertebral body chronic osteoporotic collapse. Reduced cranio-caudal height with anterior wedging of L2 vertebral body. Sagittal T1, T2 \& STIR images show isointense signal intensity of the L2 vertebra with no evidence of restricted diffusion on DWIs. ADC value: $0.429 \times 10^{-3} \mathrm{~mm}^{2} / \mathrm{s}$. 


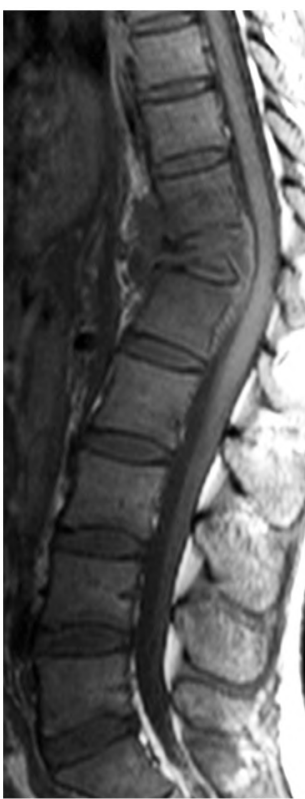

(A)

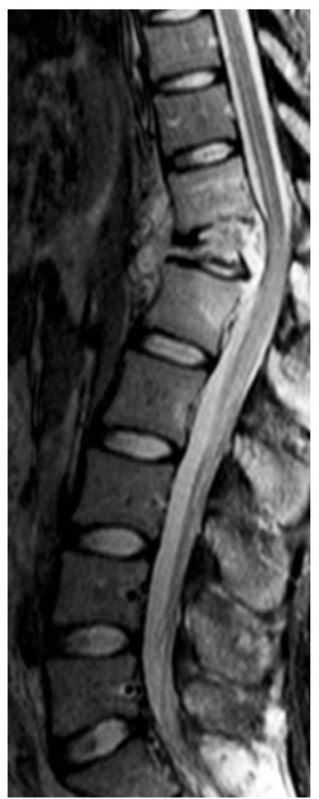

(B)

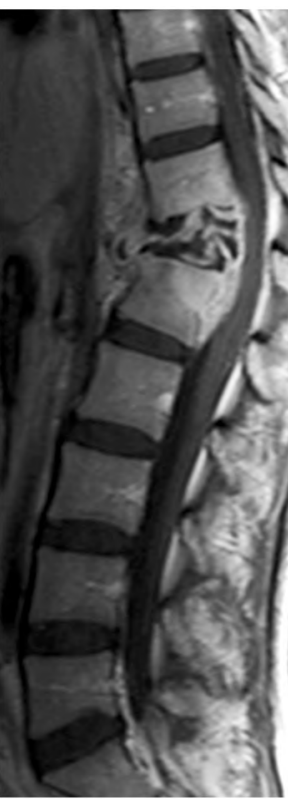

(C)

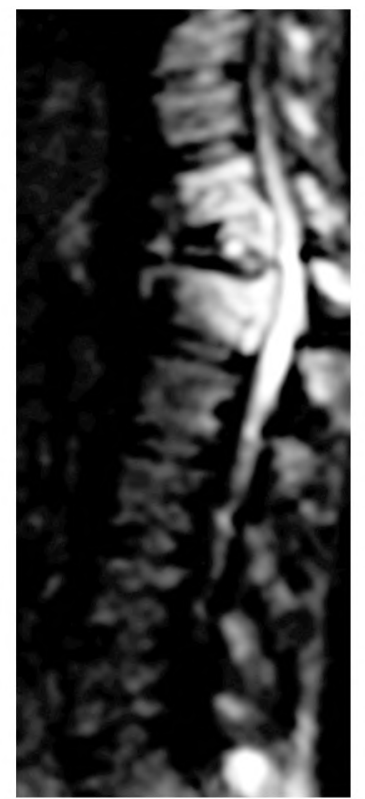

(D)

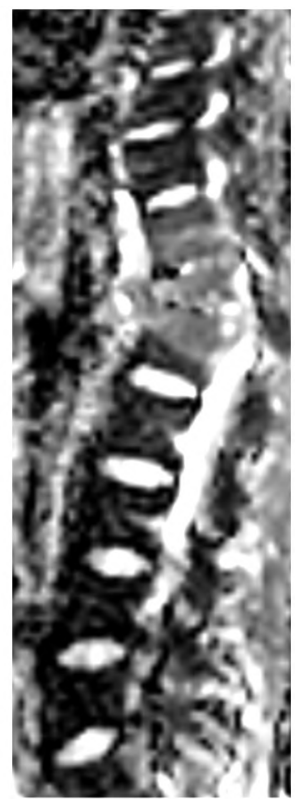

(E)

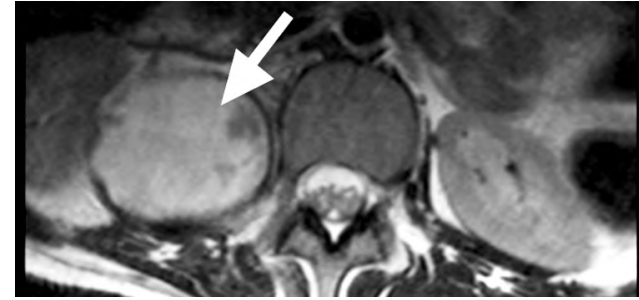

(F)

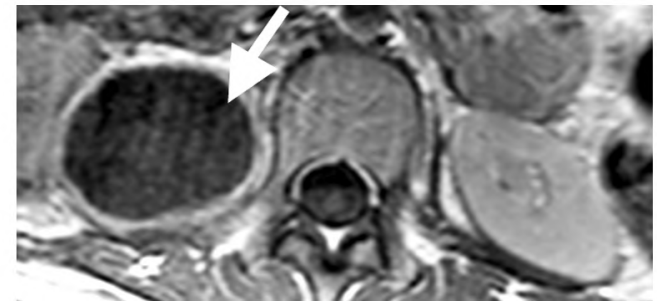

(G)

Fig. (4): 18 year old female presenting with back pain, fever, bilateral lower limb weakness. MRI of the dorsolumbar spine: (A) T1, (B) T2, (C) Post contrast T1, (D) DWI, (E) ADC sagittal images and (F) T2, (G) Post contrast T1 axial images revealing Pott's disease (tuberculous spondylodiscitis). Marked wedging and of D12 vertebra with abnormal signal of D12 and to a lesser extent D11 \& L1 vertebrae as well as the intervening D11/12 \& D12/L1 discs with heterogenous enhancement. Associated epidural and paraspinal enhancing components and a right paraspinal well-defined pȩriphęral enhancing abscess noted (arrow). On DWI, the lesion displays high signal intensity. ADC value: $1.162 \times 10 \mathrm{~mm} / \mathrm{s}$.

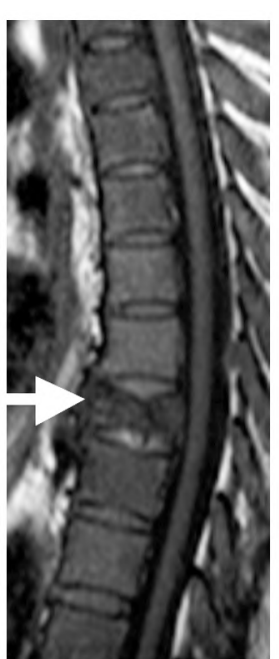

(A)

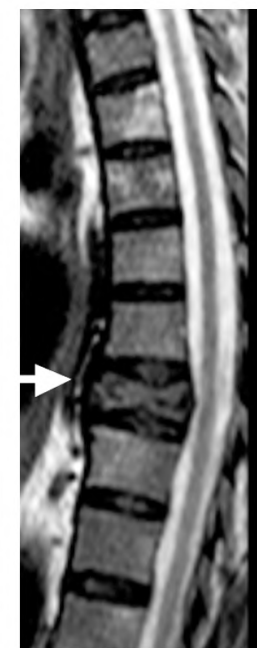

(B)

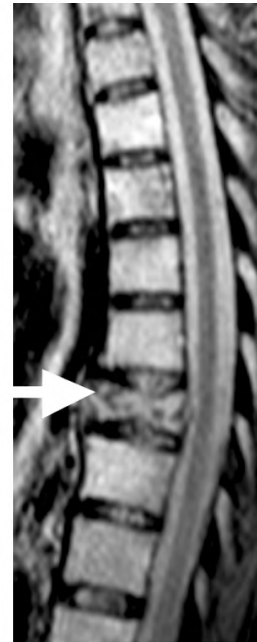

(C)

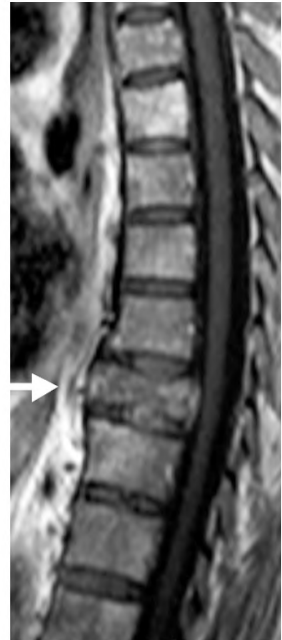

(D)

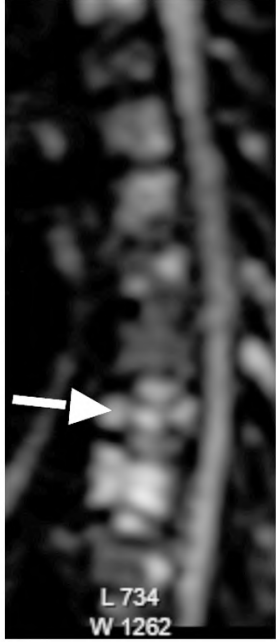

(E)

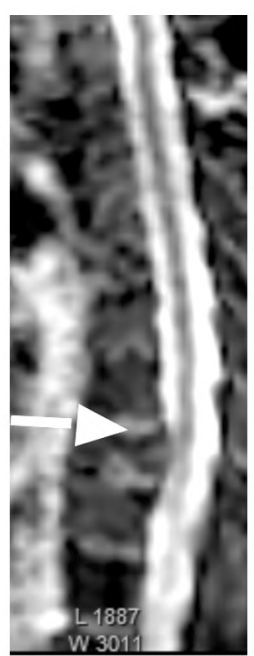

(F)

Fig. (5): 59 year old female known to have breast cancer. MRI of the dorsal spine: (A) T1, (B) T2, (C) STIR, (D) Post contrast T1 (E) DWI and (F) ADC sagittal images revealing metastatic deposits of the dorsal spine with malignant collapse of $\mathrm{D} 8$ vertebra showing restricted diffusion. ADC value: $0.825 \times 10^{-3} \mathrm{~mm}^{2} / \mathrm{s}$. 


\section{Statistical analysis:}

Data were analyzed using Statistical Program for Social Science (SPSS) Version 20.0. Quantitative data were expressed as mean \pm Standard Deviation (SD). Qualitative data were expressed as frequency and percentage.

The following tests were done:

- Independent-samples $t$-test of significance was used when comparing between two means.

- Chi-square $\left(\chi^{2}\right)$ test of significance was used in order to compare proportions between two qualitative parameters.

- Probability ( $p$-value).

- $p$-value $<0.05$ was considered significant.

- P-value <0.001 was considered as highly significant.

- $p$-value $>0.05$ was considered insignificant.

\section{Discussion}

DWI should be considered a powerful functional technique for musculoskeletal imaging. The option of contrast-free scanning certainly is of clinical significance. The principle underlying DWI is based on the measurement of the restrictions on the Brownian motion of water molecules. Water movement is relatively impeded in tightly packed tumoral cells and high cellularity tissues appear persistently bright on low and high $b$-value DWI.

Our study stated that ADC values can differentiate between benign and malignant compression fractures. In this we agreed with Fawzy et al., [6] that reported that ADC in malignancy was significantly lower than in benign processes. The mean $\mathrm{ADC}$ of the malignant pathologic vertebral compression was $0.91 \pm 0.13 \times 10^{-5} \mathrm{~mm} / \mathrm{sec}$ whereas the $\mathrm{ADC}_{-}$of acute traumatic fracture was $1.55 \pm 0.24$ $\mathrm{X} 10^{-3} \mathrm{~mm}^{2} / \mathrm{sec}$.

That was compatible with our results; the mean ADC of the malignant vertebral compression was $0.98 \pm 0.17 \times 10^{-3} \mathrm{~mm} / \mathrm{sec}$ whereas the ADC of post acute traumatic fracture was 1.5-1.7 X 10 $\mathrm{mm}^{2} / \mathrm{sec}$.

Dietrich et al., [5] also agreed with our study and stated that typical ADCs for malignant lęsions are in the range from about 0.7 to $1.3 \times 10^{-3} \mathrm{~mm} /$ $\mathrm{sec}$; the mean value calculatêd from all individual studies is $0.913 \pm 0.354 \times 10^{-3} \mathrm{~mm} / \mathrm{sec}$. In contrast, typical ADCs of benign fraçtureş are in the range from about 1.2 to $2.0 \times 10^{-3} \mathrm{~mm} / \mathrm{sec}$, with a mean value of $1.679 \pm 0.531 \times 10^{-3} \mathrm{~mm}^{2} / \mathrm{sec}$.
Baur et al., [1] reported that osteoporotic and traumatic compression fractures are hypointense in DWI relative to normal vertebral bodies and neoplastic compression fractures are hyperintense.

This was partially disagreeing with our study that stated that osteoporotic fractures are hypointense in DWI, however traumatic compression fractures are hyperintense in DWIs relative to normal vertebral bodies.

Leeds et al., [7] agreed with our study stating that benign osteopenic fractures have been reported to be hypointense on diffusion-weighted images depending on the timing of the fracture, they may be hyperintense in the acute phase due to $\mathrm{T} 2$ shinethrough.

Our study detected that chronic osteoporotic collapse ${ }_{2}$ was of low ADC values (mean $0.305 \mathrm{X}$ $10 \mathrm{~mm} / \mathrm{sec}, \mathrm{SD} \pm 0.14 \times 10^{-3} \mathrm{~mm} / \mathrm{sec}$ ) compared to the normal marrow. Yeung et al., [8], Griffith et al., [9], Hatipoglu et al., [10] and Tang et al., [11] agreed with our study that a slight decrease of the $\mathrm{ADC}$ with increasing degrees of osteoporosis (i.e. with decreasing bone mineral density and increasing fat fraction) was observed. Yehya et al., [12] stated that the ADC of the vertebral lesions which were diagnosed as old traumatic or old osteoporotic fractures were similar to that on normal vertebral body.

\section{Conclusion:}

Diffusion weighted MRI can be used as a reliable tool in differentiation between different causes of vertebral body collapse. DWI could be applied as a cost effective substitute for the gadolinium enhanced scan especially in patients with contraindication for contrast administration.

\section{References}

1- BAUR A., STABLER A., BRUNING R., BARTL R., KRODEL A., REISER M. and DEIMLING M.: Diffusionweighted MR imaging of bone marrow: Differentiation of benign versus pathologic compression fractures. Radiology, 207: 349-56, 1998.

2- GEITH T., SCHMIDT G., BIFFAR A., DIETRICH O., DURR H.R., REISER H. and BAUR-MELNYK A.: Comparison of Qualitative and Quantitative Evaluation of Diffusion-Weighted MRI and Chemical-Shift Imaging in the Differentiation of Benign and Malignant Vertebral Body Fractures A.J.R, 199: 1083-92, 2012.

3- DALLAUDIÈRE B., DAUTRY R., PREUX P., PEROZZIELLO A., LINCOT J., SCHOUMAN-CLAEYS A. and SERFATY J.: Comparison of apparent diffusion coefficient in spondylarthritis axial active inflammatory 
lesions and type 1 modic changes. European Journal of Radiology, 83: 366-70, 2014.

4- KHOO M.M., TYLER P.A. and SAIFUDDIN A.: Diffusion-Weighted Imaging (DWI) in musculoskeletal MRI: a critical review. Skeletal Radiology; 40: 665-81, 2011.

5- DIETRICH O., GEITH T., REISER M.F. and BAURMELNYK A.: Diffusion imaging of the vertebral bone marrow. NMR Biomed, 2015.

6- FAWZY F., TANTAWY H.I., RAGHEB A. and ABO HASHEM S.: Diagnostic value of apparent diffusion coefficient to differentiate benign from malignant vertebral bone marrow lesions. The Egyptian Journal of Radiology and Nuclear Medicine, 44: 265-71, 2013.

7- LEEDS N.E., KUMAR A.J., ZHOU X.J. and McKINNON G.C.: Magnetic Resonance Imaging of Benign Spinal Lesions Simulating Metastasis: Role of DiffusionWeighted Imaging. Topics in Magnetic Resonance Imaging, 11 (4): 224-34, 2000.

8- YEUNG D.K., WONG S.Y., GRIFFITH J.F. and LAU E.M.: Bone marrow diffusion in osteoporosis: Evaluation with quantitative MR diffusion imaging. J. Magn. Reson. Imaging, 19: 222-8, 2004.

9- GRIFFITH J.F., YEUNG D.K., ANTONIO G.E., WONG S.Y., KWOK T.C., WOO J. and LEUNG P.C.: Vertebral marrow fat content and diffusion and perfusion indexes in women with varying bone density: MR evaluation. Radiology, 241: 831-8, 2006.

10- HATIPOGLU H.G., SELVI A., CILIZ D. and YUKSEL E.: Quantitative and diffusion MR imaging as a new method to assess osteoporosis. Am. J. Neuroradiol., 28: 1934-7, 2007.

11- TANG G.Y., LV Z.W., TANG R.B., LIU Y., PENG Y.F., LI W. and CHENG Y.S.: Evaluation of MR spectroscopy and diffusion-weighted MRI in detecting bone marrow changes in postmenopausal women with osteoporosis. Clin. Radiol., 65: 377-81, 2010.

12- YEHYA A., EL-SHEIKH M., BARAKAT M.S. and ABD EL-SALAM M.: Collapsed Vertebrae: New Diagnostic Modality for Better Management. Egyptian Journal of Neurosurgery, 29 (3): 59-66, 2014.

\title{
إستخدام الرنين الهغناطيسى بطريقة الإنتشار للتفرقة بين الآسباب الحميدة والخبيثة لحلدوث كسر منضغط بالغين بالفقرات
}

\author{
عند إستخدام الرنين المغناطيسى التقليدى، لا توجد إختلافات موثققة تتيح التمييز ما بين كسر منضغط بالفقرات ناتج عن هشاشية العظام

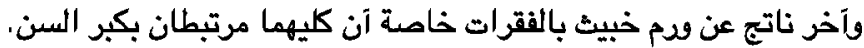 \\ لذلك كان من المهم إيجاد معايير نوية آو كمية إضافة للتمييز الآكثر موثقية بين هذين النومين من الكسر. \\ القفنية الجديدة عن طريق إستخدام الرنين المغناطيسى بطريقة الإنتشار جنبا إلى جنب مع قياس معامل الإنتثار الظاهر توفر معلومات

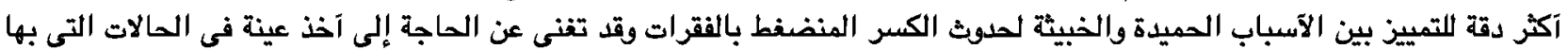

